\title{
SPECTRUM OF PERFORATION PERITONITIS AT A TERTIARY CARE CENTRE IN PUNJAB
}

\author{
Varun Gupta1, Chiranjiv Singh Gill², Sanjeev Kumar Singla³, Manvi Gupta ${ }^{4}$ \\ ${ }_{1}^{1}$ Associate Professor, Department of Surgery, DMC and H, Ludhiana, Punjab. \\ 2 Professor, Department of Surgery, DMC and H, Ludhiana, Punjab. \\ 3 Professor, Department of Surgery, DMC and H, Ludhiana, Punjab. \\ ${ }^{4}$ Consultant Pathologist, ESIC, Model Hospital, Ludhiana, Punjab.
}

ABSTRACT

\section{BACKGROUND}

Perforation peritonitis is the most common surgical emergency encountered by the surgeons all over the world. It requires an urgent surgical intervention and is a significant cause of morbidity and mortality. The present study was carried out to analyse the frequency, aetiology and common sites of secondary perforation peritonitis in our setup.

\section{MATERIALS AND METHODS}

This study was conducted as a descriptive study analysing 426 patients of secondary peritonitis from July 2012 till June 2017 at Dayanand Medical College and Hospital, Ludhiana. All cases found to have peritonitis as a result of perforation of any part of gastrointestinal tract at the time of surgery were included in the study. All cases with either primary peritonitis or that due to anastomotic dehiscence were excluded.

\section{RESULTS}

A total of 426 patients were studied, which included 328 males and 98 females. Majority (89\%) of the patients were in the third and fourth decades of life. Pain was the commonest presenting symptom. Most common site of perforation was small intestine with $44.3 \%$ cases in ileum, $23 \%$ in duodenum and $4 \%$ in jejunum and the commonest associated risk factor was typhoid (40.3\%). Overall, the mortality rate was $20.6 \%$.

\section{CONCLUSION}

Majority of perforation peritonitis cases in the study comprised of typhoid ileal perforations, which leads to the realisation of the impending need to strengthen the hygienic conditions in the area. Overall morbidity and mortality were acceptable. The basic principles of early diagnosis, prompt resuscitation and urgent surgical intervention still form the cornerstones of management in these cases.

\section{KEY WORDS}

Aetiology, Perforation, Peritonitis.

HOW TO CITE THIS ARTICLE: Gupta V, Gill CS, Singla SK, et al. Spectrum of perforation peritonitis at a tertiary care centre in Punjab. J. Evolution Med. Dent. Sci. 2018;7(20):2433-2436, DOI: 10.14260/jemds/2018/547

\section{BACKGROUND}

Perforation peritonitis is one of the commonest lifethreatening surgical emergencies. Despite advancements in diagnosis, surgical techniques, antimicrobial therapy and intensive care support, management of peritonitis continues to be highly demanding, difficult and complex.[1,2] Peritonitis can be classified as primary, secondary or tertiary depending upon the source and nature of microbial contamination. Primary peritonitis occurs mainly through haematogenous dissemination, secondary peritonitis is caused by resident flora subsequent to the loss of integrity of a hollow viscus, while non-responding secondary peritonitis either due to failure of the host inflammatory response or overwhelming superinfection leads to tertiary peritonitis.[3] It usually presents as an acute abdomen and the local findings include abdominal tenderness, guarding or rigidity, distension or

'Financial or Other Competing Interest': None.

Submission 03-04-2018, Peer Review 01-05-2018,

Acceptance 07-05-2018, Published 14-05-2018.

Corresponding Author:

Dr. Manvi Gupta,

\#28-B, Tagore Nagar,

Opposite Hero DMC Heart Institute,

Ludhiana-141001, Punjab.

E-mail: guptamanvi81@yahoo.com

DOI: $10.14260 /$ jemds $/ 2018 / 547$ diminished bowel sounds. Systemically, there may be fever, chills/rigor, tachycardia, tachypnoea, restlessness, dehydration, oliguria, disorientation. The contamination of the peritoneal cavity leads to a cascade of infection, sepsis, multisystem organ failure and death if not treated timely. The diagnosis is based mainly on clinical grounds. Plain x-ray, ultrasound and CT scan are the tools that can ascertain the diagnosis. The aim of the present study was to analyse the frequency, aetiology and common sites of secondary perforation peritonitis in our setup.

\section{MATERIALS AND METHODS}

This study was conducted as a descriptive study analysing 426 patients of secondary peritonitis from July 2012 till June 2017 at Dayanand Medical College and Hospital, Ludhiana.

\section{Inclusion Criteria}

All cases found to have peritonitis as a result of perforation of any part of gastrointestinal tract at the time of surgery were included in the study.

\section{Exclusion Criteria}

All cases with either primary peritonitis, corrosive and postoperative peritonitis due to anastomotic leakage were excluded. 
All the cases were studied in terms of clinical presentation, radiological investigations, operative findings identifying the cause and site of perforation and postoperative course. Following a clinical diagnosis of perforation peritonitis and adequate resuscitation, all the patients underwent emergency exploratory laparotomy. After opening the abdomen, the source of contamination was identified and treated accordingly. The peritoneal lavage was done with copious amount of warm normal saline. Abdomen was closed and decision to insert a drain was left to the discretion of the operating surgeon. Postoperatively, all the patients received appropriate broad-spectrum antibiotics along with intravenous fluid. However, the drug regimen was not uniform in all patients.

\section{RESULTS}

A total of 426 patients were included in this study. There were $328(77 \%)$ males and 98 (23\%) females. The age ranged from 18 to 75 years with the maximum incidence $(89 \%)$ in the third and fourth decade. Various signs and symptoms and investigative findings are depicted in Table 1.

\begin{tabular}{|c|c|}
\hline $\begin{array}{c}\text { Clinical } \\
\text { Presentation }\end{array}$ & $\begin{array}{c}\text { No. of } \\
\text { Cases }\end{array}$ \\
\hline Pain & $426(100 \%)$ \\
\hline Nausea/ Vomiting & $389(91.3 \%)$ \\
\hline Abdominal distension & $360(84.5 \%)$ \\
\hline Constipation & $285(67 \%)$ \\
\hline Fever & $176(41.3 \%)$ \\
\hline Shock & $142(33.3 \%)$ \\
\hline Septicaemia & $112(26.29 \%)$ \\
\hline Abdominal tenderness & $376(88.2 \%)$ \\
\hline Abdominal rigidity & $352(82.6 \%)$ \\
\hline Investigations & $173(56 \%)$ \\
\hline Hyponatraemia (Na < 130 mEq/L) & $139(45 \%)$ \\
\hline Hypokalaemia (K < 2.7 mEq/L) & $82(26 \%)$ \\
\hline Serum Creatinine (<1.7 mg/dL) & $104(33 \%)$ \\
\hline Pheod Urea Nitrogen (> 167 mg/dL) & $164(53 \%)$ \\
\hline Air fluid levels on abdominal x-ray & $90(29 \%)$ \\
\hline Table 1. Clinical Presentation and Investigative \\
Abnormalities \\
\hline
\end{tabular}

All 426 patients underwent emergency laparotomy. The sites and aetiology of perforation are shown in Table 2 and 3 respectively.

\begin{tabular}{|c|c|}
\hline Site & No. of Cases \\
\hline Gastric & $61(14.4 \%)$ \\
\hline Small Intestine & $303(71.1 \%)$ \\
Ileum & $188(44.1 \%)$ \\
Duodenum & $98(23 \%)$ \\
Jejunum & $17(4 \%)$ \\
\hline Appendix & $35(8.2 \%)$ \\
\hline Colon & $23(5.4 \%)$ \\
\hline Gall Bladder & $3(0.7 \%)$ \\
\hline Meckel's Perforation & $1(0.2 \%)$ \\
\hline \multicolumn{2}{|c|}{ Total } \\
\hline \multicolumn{2}{|c|}{ Table 2. Sites of Perforation } \\
\hline
\end{tabular}

\begin{tabular}{|c|c|}
\hline Cause & No. of Cases \\
\hline Typhoid & $172(40.3 \%)$ \\
\hline Acid peptic disease & $91(21.4 \%)$ \\
\hline Tuberculosis & $55(12.9 \%)$ \\
\hline Trauma & $47(11.0 \%)$ \\
\hline Appendicitis & $35(8.2 \%)$ \\
\hline Malignancy & $14(3.4 \%)$ \\
\hline Other infections/ inflammations & $12(2.8 \%)$ \\
\hline Total & $\mathbf{4 2 6}$ \\
\hline Table 3. Causes of Perforation \\
\hline
\end{tabular}

Generalised peritonitis was found in 294 (69\%) cases, while the remaining 132 (31\%) had localised peritonitis. Faecal exudate was seen in $35(84 \%)$ patients, while 68 (16\%) cases had either clear or purulent exudate. Table 4 summarises the surgical procedures performed.

\begin{tabular}{|c|c|}
\hline Surgical Procedure Performed & No. of Cases \\
\hline Ileostomy & $238(55.8 \%)$ \\
\hline Omentopexy & $69(16.4 \%)$ \\
\hline Resection and anastomosis & $67(15.7 \%)$ \\
\hline Appendicectomy & $35(8.2 \%)$ \\
\hline Colostomy & $8(1.8 \%)$ \\
\hline Colectomy & $6(1.4 \%)$ \\
\hline Cholecystectomy & $3(0.7 \%)$ \\
\hline Total & $\mathbf{4 2 6}$ \\
\hline Table 4. Surgical Procedures Performed
\end{tabular}

Postoperative complications were encountered in 215 $(50.4 \%)$ cases (Table 5). The overall mortality in this study was $88(20.6 \%)$.

\begin{tabular}{|c|c|}
\hline Complication & No. of Cases \\
\hline Wound infection & $143(33.5 \%)$ \\
\hline Respiratory complication & $126(29.5 \%)$ \\
\hline Septicaemia & $93(21.8 \%)$ \\
\hline Electrolyte Imbalance & $87(20.4 \%)$ \\
\hline Wound dehiscence & $47(11 \%)$ \\
\hline Abdominal collection & $45(10.5 \%)$ \\
\hline Anastomotic leak & $33(7.7 \%)$ \\
\hline \multicolumn{2}{|c|}{ Table 5. Postoperative Complications } \\
\hline
\end{tabular}

\section{DISCUSSION}

Generalised peritonitis is a frequently encountered emergency and remains a significant cause of morbidity and mortality, which usually requires emergency surgery.[4] Majority of the patients present late with purulent peritonitis and septicaemia.[5] Worldwide, there is a predominance of males presenting with this life-threatening disease.[6,7] A similar trend was observed in our study with a male: female ratio of 3.3: 1 . Mean age of presentation was 45.5 years with an age range from 18 - 75 years. This was almost equivalent to the mean age of 49 years found by Singh et al,[8] while an age range of 36.8 to 60 years has been observed in various studies. $[8,9,10]$

The diagnosis of patients with peritonitis is clinical and the patients present with variable symptoms. All patients in our study presented with pain which was sharp, constant, intense and aggravated with movement. Other symptoms included nausea/ vomiting, constipation, abdominal distension and shock. Memon et al[11] reported similar symptoms in their study. Investigations in patients with peritonitis have dubious reliability. Only $50 \%$ patients in our study had evidence of pneumoperitoneum on $\mathrm{x}$-ray chest and 
29\% showed air fluid levels on x-ray abdomen. This corresponds well with another study, which reports pneumoperitoneum in $52.7 \%$ cases and air fluid levels in $28.9 \%$ cases.[12] $^{[1]}$

The most common site of perforation was small intestine with majority (44.1\%) involving the ileum. This is corroborated by similar studies conducted by Quereshi et al[13] and Memon et al.[11] In contrast to this, Jhobta et al[6] and Dorairajan et al[14] observed the perforations of proximal gastrointestinal tract to be 6 times as common as distal tract.

The most common cause of secondary peritonitis was typhoid followed by peptic ulcer disease. Similar results were obtained by Memon et al,[11] Chaterjee ${ }^{[15,16]}$ and Khanna et al.[17] Noon et al[18] observed $48.9 \%$ cases to be due to penetrating trauma, $21.39 \%$ due to appendicitis and $15.81 \%$ due to peptic ulcer. This shows that whereas infection is the major cause of perforations in developing countries. The developed countries have an entirely different spectrum. Poor hygiene, low socio-economic status and illiteracy are the main reasons for such a high rate of infection and steps should be taken to improve these.

Primary closure with proximal ileostomy was done in majority of the cases of typhoid ileal perforation who presented late and had faecal contamination of the peritoneal cavity, friable gut, poor clinical condition which is also supported by other studies.[19-22] Acid peptic disease was the second commonest cause of perforation requiring an early surgery for a favourable outcome. We found that in such cases the closure of perforation using a Graham's omental patch was a simple procedure with low mortality as supported by Subramanyam et al.[23] Primary intestinal tuberculosis is common in developing countries like India as compared to the western countries. Extrapulmonary tuberculosis most commonly affects the ileocaecal region and the terminal ileum. Perforation occurs in the ulcerative type of tuberculosis.[24,25] $12.9 \%$ of the cases in our study were tubercular perforations and were managed by resection and anastomosis of small gut or stoma.[26,27] Traumatic perforations accounted for $11 \%$ of all causes, which is comparable with the $9 \%$ incidence shown by Jhobta et al.[6] Road traffic accidents were major cause of traumatic perforations in this study and majority were treated by resection and anastomosis. Appendicular perforations were seen in $8.2 \%$ cases comparable to other studies that showed an incidence of $5 \%$ to $13.7 \% .[6,9]$ Appendicectomy, peritoneal toileting and systemic antibiotics were used in all cases. 14 cases of malignancy were found in our study with majority involving the large bowel and were treated by resection and anastomosis, colectomy or stoma.

In our study, the commonest postoperative complication was wound infection occurring in $33.5 \%$ cases. This was in comparison to $28 \%$ and $25 \%$ wound infections reported by Memon et al[11] and Jhobta et al,[6] respectively. The higher incidence of wound infection may be because majority of patients presented late ( $>72$ hours) to the hospital with wellestablished peritonitis and many patients had pre-operative co-morbidities and morbidity was higher among them. Overall mortality in this study was $20.6 \%$ and similar mortality was reported by Memon et al.[11] The mortality rates reported by various studies in literature vary from $6 \%$ to $38 \%,[6,9,28]$ The high mortality in our setup could be attributed to the fact that being a tertiary care centre this hospital caters to all distant rural areas of the state. Illiteracy, low socio-economic status, improper infrastructure including inadequate transport and delayed referral to tertiary care hospital by the general practitioners are some of the reasons for these patients coming late. Delayed presentation to a definitive care hospital is definitely the prime cause of losing the patient to this dreadful emergency.

\section{CONCLUSION}

The majority of perforation peritonitis cases in the study comprised of typhoid ileal, peptic ulcer, appendicular and traumatic perforations. Typhoid perforations are the commonest cause. This leads to the realisation of the impending need to strengthen the hygienic conditions in the area. Overall morbidity and mortality were acceptable. However, in moribund patients and in cases of extremely delayed presentation, worse outcomes were noted. The basic principles of early diagnosis, prompt resuscitation and urgent surgical intervention still form the cornerstones of management in these cases.

\section{ACKNOWLEDGEMENTS}

The authors especially thank all the medical and non-medical staffs of the department and hospital for their sincere work and cordial cooperation with this project.

\section{REFERENCES}

[1] Adesunkanmi ARK, Badmus TA, Fadiora FO, et al. Generalised peritonitis secondary to typhoid ileal perforation: assesment of severity using modified APACHE II score. Indian J Surg 2005;67:29-33.

[2] Dorairajan LN, Gupta S, Deo SSV, et al. Peritonitis in India--a decade's experience. Trop Gastroenterol 1995;16(1):33-8.

[3] Simmen HP, Heinzelmann M, Largiader F. Peritonitis: classification and causes. Dig Surg 1996;13:381-3.

[4] Langell JT, Mulvihill SJ. Gastrointestinal perforation and the acute abdomen. Med Clin North Am 2008;92(3):599-625.

[5] Ersumo T, W/Meskel Y, Kotisso B. Perforated peptic ulcer in Tikur Anbessa Hospital: a review of 74 cases. Ethiop Med J 2005;43(1):9-13.

[6] Jhobta RS, Attri AK, Kaushik R, et al. Spectrum of perforation peritonitis in India - review of 504 consecutive cases. World J Emerg Surg 2006;1:26.

[7] Wani RA, Parray FQ, Bhat NA, et al. Nontraumatic terminal ileal perforation. World J Emer Surg 2006;1:7.

[8] Singh G, Sharma RK, Gupta R. Gastrointestinal perforations - a prospective study of 342 cases. Gastroentrol Today 2006;10(4):167-70.

[9] Afridi SP, Malik F, Ur-Rahaman S, et al. Spectrum of perforation peritonitis in Pakistan: 300 cases of Eastern experience. World J Emerg Surg 2008;3:31.

[10] Patil PV, Kamat MM, Hindalekar MM. Spectrum of perforative peritonitis - a prospective study of 150 cases. Bombay Hospital J 2012;54(1):38-50.

[11] Memon AA, Siddiqui FG, Abro AH, et al. An audit of secondary peritonitis at a tertiary care university hospital of Sindh, Pakistan. World J Emerg Surg 2012;7:6.

[12] Conroy JV. Acute ileitis with ulceration and perforation due to paratyphoid fever: report of eighty-five cases. Mil Med 1957;120(2):79-92. 


\section{Jemds.com}

[13] Quereshi AM, Zafar A, Saeed K, et al. Predictive power of Mannheim peritonitis index. J Coll Physicians Surg Pak 2005;15(11):693-6.

[14] Dandapat MC, Mukherjee LM, Mishra SB, et al. Gastrointestinal perforations. Indian J Surg 1991;53:189-93.

[15] Chaterjee H, Jagdish S, Pai D, et al. Changing trends in outcome of typhoid ileal perforations over three decades in Pondicherry. Trop Gastroenterol 2001;22(3):155-8.

[16] Chaterjee H, Pai D, Jagdish S, et al. Pattern of nontyphoid ileal perforation over three decades in Pondicherry. Trop Gastroenterol 2003;24(3):144-7.

[17] Khanna AK, Mishra MK. Typhoid perforation of the gut. Postgrad Med J 1984;60(706):523-5.

[18] Noon GP, Beall AC, Jorden GL. Clinical evaluation of peritoneal irrigation with antibiotic solution. Surgery 1967;67:73.

[19] Adensunkanni AR, Ajao OG. The prognostic factors in typhoid ileal perforation: a prospective study of 50 patients. J R Coll Surg Edinb 1997;42(6):395-9.

[20] Maurya SD, Gupta HC, Tiwari A, et al. Typhoid bowel perforation: a review of 264 cases. Int Surg 1984;69(2):155-8.

[21] Meier DE, Imediegwu 00, Tarpley JL. Perforated typhoid enteritis: operative experience with 108 cases. Am J Surg 1989;157(4):423-7.

\section{Original Research Article}

[22] Eustache JM, Kreis DJ Jr. Typhoid perforation of the intestine. Arch Surg 1983;118(11):1269-71.

[23] Subramanyam SG, Sunder N, Saleem KM, et al. Peritonitis in patients over the age of 50 years: 98 cases managed surgically. Trop Doct 2005;35(4):24750.

[24] Sharma MP, Bhatia V. Abdominal tuberculosis. Indian J Med Res 2004;120(4):305-15.

[25] Kasahara K, Fukuoka A, Murakawa K, et al. Tuberculous peritonitis developing during chemotherapy for pulmonary and intestinal tuberculosis: a case report. Respirology 2005;10(2):257-60.

[26] Ara C, Sogutlu G, Yildiz R, et al. Spontaneous small bowel perforation due to intestinal tuberculosis should not be repaired by simple closure. J Gastrointest Surg 2005;9(4):514-7.

[27] Ramesh J, Banait GS, Ormerod LP. Abdominal tuberculosis in a district general hospital: a retrospective review of 86 cases. QJM 2008;10(3):18995.

[28] Gupta SK, Gupta R, Singh G, et al. Perforation peritonitis: a two year experience. JK Science 2010;12(3):141-4. 